SHORT REPORT

\title{
How international are leading general paediatric journals? O Tutarel
}

The composition of the editorial boards of leading general paediatric journals was assessed. The board members' country of current affiliation was classified according to the Human Development Index. The results showed that only a very small number of the board members are based in the developing world.

O ne of the millennium development goals of the United Nations is the reduction of child mortality by two thirds by $2015 .^{1}$ Academic and research institutions, and professional and scientific associations must contribute their efforts and expertise to child survival and should place their power and credibility behind the child survival agenda. ${ }^{1}$ Medical journals have an important role in this effort, but their credibility concerning the problems of the developing world is questionable. Richard Horton, editor of The Lancet, stated that there is widespread systematic bias in medical journals against diseases that dominate the least developed regions of the world, ${ }^{2}$ an argument also brought forward by researchers from these regions. ${ }^{3}$ As a first step towards examining the objective basis for this claim, researchers from the World Health Organization investigated the composition of the editorial boards of leading psychiatry journals and found an under-representation of individuals from developing world countries. ${ }^{3}$ General medical and tropical medicine journals followed the same pattern. ${ }^{24}$

In this study, the composition of the editorial boards of leading general paediatric journals was investigated to evaluate the situation in paediatrics.

\section{METHODS}

The leading journals in the field of general paediatrics were defined as all journals that were included in the "Pediatrics" category of the 2003 Journal Citation Report, Science Edition, and that were general paediatric journals; speciality journals such as Pediatric Cardiology were excluded. The geographical composition of the editorial boards of these journals was retrieved from their electronic homepages in February 2005.

The countries in which the board members are currently based were classified according to their Human Development Index (HDI), which combines measures of life expectancy, school enrolment, literacy and income to allow a broader view of a country's development than does income alone (Human Development Report 2004; http://hdr.undp.org/).

\section{RESULTS}

Of the 68 journals from the 'Pediatrics' category of the Journal Citation Report, 11 remained for further analysis once the criteria used for the definition of leading general paediatric journals were applied, and in total, 207 editorial board members were found. Of these, $198(95.7 \%)$ were based in countries with a high HDI and $8(3.9 \%)$ in countries with a medium HDI. No board member was based in a country with a low HDI. One member of the International Advisory Board of the journal Pediatrics International is currently based in Taiwan, which is not classified in the Human Development Report 2004 and therefore has no HDI. Results for each journal can be found in table 1 (for more detailed results refer to the supplementary material; available from the Archives of Diseases in Childhood website at http://www.archdischild.com/ supplemental).

\section{DISCUSSION}

The analysis of the composition of the editorial boards of leading general paediatric journals reveals that $95.7 \%$ of their members are based in countries with a high HDI, 3.9\% in countries with a medium HDI, and none in a country with a low HDI. These results are in accordance with previously reported figures. ${ }^{2-4}$ While Horton found that only $1.8 \%$ of editorial board members of leading general medical journals were from countries with a low HDI, and 5.4\% from countries with a medium HDI, $92.8 \%$ of the members were based in countries with a high HDI. ${ }^{2}$ The figures for leading tropical medicine journals are slightly better, with $70.8 \%, 24.1 \%$, and $5.1 \%$ for countries with high, medium, and low HDI, respectively. ${ }^{4}$ Therefore, the numbers for leading general paediatric journals are the worst.

The theory that a low proportion of editorial advisers from developing countries is evidence of a bias against the work of researchers from this part of the world, remains to be

Table 1 Composition of the editorial boards of 11 leading general paediatric journals

\begin{tabular}{|c|c|c|c|c|}
\hline \multirow[b]{2}{*}{ Journal } & \multirow{2}{*}{$\begin{array}{l}\text { Total no. } \\
\text { of board } \\
\text { members }\end{array}$} & \multicolumn{3}{|c|}{$\begin{array}{l}\text { No }(\%) \text { of board members } \\
\text { classified according to the HDI } \\
\text { of the country of current } \\
\text { affiliation }\end{array}$} \\
\hline & & High & Medium & Low \\
\hline Acta Paediatrica* & 27 & $26(96.3)$ & $1(3.7)$ & $0(0)$ \\
\hline $\begin{array}{l}\text { Archives of Disease in } \\
\text { Childhood }^{*}\end{array}$ & 12 & $12(100)$ & $0(0)$ & $0(0)$ \\
\hline $\begin{array}{l}\text { Archives of Pediatrics } \\
\& \text { Adolescent } \\
\text { Medicinet }\end{array}$ & 15 & $15(100)$ & $0(0)$ & $0(0)$ \\
\hline Clinical Pediatricst & 19 & $19(100)$ & $0(0)$ & $0(0)$ \\
\hline $\begin{array}{l}\text { European Journal of } \\
\text { Pediatrics } ¥\end{array}$ & 8 & $8(100)$ & $0(0)$ & $0(0)$ \\
\hline $\begin{array}{l}\text { Journal of Adolescent } \\
\text { Healtht }\end{array}$ & 27 & $27(100)$ & $0(0)$ & $0(0)$ \\
\hline $\begin{array}{l}\text { Journal of Paediatrics } \\
\text { and Child Health§ }\end{array}$ & 10 & $10(100)$ & $0(0)$ & $0(0)$ \\
\hline Journal of Pediatrics & 23 & $22(95.7)$ & $1(4.3)$ & $0(0)$ \\
\hline Pediatric Research ${ }^{\star *}$ & 18 & $18(100)$ & $0(0)$ & $0(0)$ \\
\hline Pediatricst & 23 & $23(100)$ & $0(0)$ & $0(0)$ \\
\hline Pediatrics & 25 & $18(72)$ & $6(24)$ & $0(0)$ \\
\hline International†† & & & & \\
\hline Total & 207 & $198(95.7)$ & $8(3.9)$ & $0(0)$ \\
\hline
\end{tabular}


proven. $^{5}$ Keiser et al showed that in tropical medicine journals, the proportion of authors from developing world countries is higher than the proportion of researchers from these countries on the editorial boards of these journals. ${ }^{4}$ In addition, the content of a journal may reflect issues related to poor countries irrespective of the composition of its editorial board. Therefore, a limitation of this study is that the content of the leading general paediatric journals was not evaluated. It must also be kept in mind that editorial boards have a variable part to play in decision making about research papers and editorial policy, with some having little influence. ${ }^{2}$ Their influence on what kind of manuscripts are submitted is probably even smaller.

The importance of editorial boards lies in the fact that they can help to shape the personalities of journals, and that their composition sends a signal to authors and readers about a journal's interest. ${ }^{2}$ Concerning the composition of editorial boards of leading general paediatric journals, the signal sent out to researchers in the developing world is not encouraging, and indeed, tends to support the theory of an editorial bias against the problems of the developing world.

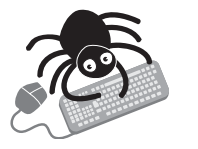

Supplementary material is available from the $A D C$ website at http://www.archdischild.com/ supplemental

\section{Competing interests: none}

Correspondence to: $\operatorname{Dr} O$ Tutarel, Geibelstr. 76, 30173 Hannover, Germany; otutarel@hotmail.com

Accepted 7 March 2005

\section{REFERENCES}

1 The Bellagio Study Group on Child Survival. Knowledge into action for child survival. Lancet 2003;362:323-7.

2 Horton R. Medical journals: evidence of bias against the diseases of poverty. Lancet 2003:361:712-13.

3 Saxena S, Levar I, Maulik P, et al. How international are the editorial boards of leading psychiatry journals? Lancet 2003;361:609.

4 Keiser J, Utzinger J, Tanner M, et al. Representation of authors and editors from countries with different human development indexes in the leading literature on tropical medicine: survey of current evidence. BMJ 2004;328:1229-32.

5 Wilkinson G. How international are the editorial boards of leading psychiatry journals? Lancet 2003;361:1229.

\section{ARCHIVIST}

\section{Treatment of infantile spasms}

Infantile spasms are usually treated with either steroid (oral corticosteroid or intramuscular adrenocorticotropic hormone) or vigabatrin. These treatments have been compared in a UK multicentre trial (Andrew L Lux and colleagues. Lancet 2004;364: $1773-8)$

A total of 107 infants aged 2-12 months with infantile spasms (not due to tuberous sclerosis) were randomised $(2: 1: 1)$ at 150 centres to vigabatrin, prednisolone, or tetracosactide. Vigabatrin dosage was $25 \mathrm{mg} / \mathrm{kg}$ twice on day 1 and $50 \mathrm{mg} / \mathrm{kg}$ twice daily from day 2, increasing to $75 \mathrm{mg} / \mathrm{kg}$ twice daily from day 5 if spasms persisted. Prednisolone dosage was $10 \mathrm{mg}$ four times daily, increasing if spasms persisted to $20 \mathrm{mg}$ three times daily in the second week. Tetracosactide was given intramuscularly in a dose of $0.5 \mathrm{mg}$ (40 IU) on alternate days, increasing if spasms persisted to $0.75 \mathrm{mg}$ on alternate days in the second week. Each of the steroid groups received treatment for 2 weeks after which a tailing dose of prednisolone was given over a period of 15 days. Infants with tuberous sclerosis were excluded because of evidence that they are best treated with vigabatrin.

Treatment success (no spasms on days 13 and 14) was achieved for 28/52 (54\%) in the vigabatrin group, $21 / 30(70 \%)$ in the prednisolone group, and $19 / 25(76 \%)$ in the tetracosactide group - a significant difference between the vigabatrin and the steroid groups. There was no significant difference between the two steroid groups. Of the 107 EEGs $83(78 \%)$ showed hypsarrhythmia and 21 "almost hypsarrhythmia". Spasms stopped in 53/ $83(64 \%)$ with hypsarrhythmia and 15/24 (63\%) without hypsarrhythmia. Hypsarrhythmia resolved significantly more often with steroid treatment $(26 / 32,81 \%)$ than with vigabatrin $(20 / 36,56 \%)$. The rates of treatment success were similar in symptomatic and cryptogenic infantile spasms. The incidence of adverse events was similar in the steroid and vigabatrin groups. Irritability was more common with steroid treatment and drowsiness with vigabatrin. Five of the 55 infants in the steroid groups developed fluid and electrolyte problems including high blood pressure.

Steroid treatment (prednisolone or tetracosactide) was more likely than vigabatrin to result in cessation of spasms and more likely to induce resolution of hypsarrhythmia. The long term results of the trial are to be reported. 